\title{
Direct Transformation of Terminal Alkynes into Amidines by a Sil- ver-Catalyzed Four-Component Reaction
}

\author{
Binbin Liu, ${ }^{\S a}$ Yongquan Ning, ${ }^{\S a}$ Matteo Virelli, ${ }^{c}$ Giuseppe Zanoni, ${ }^{c}$ Edward A. Anderson ${ }^{d}$ and Xihe \\ $\mathrm{Bi} * a, b$
}

${ }^{a}$ Department of Chemistry, Northeast Normal University, Changchun 130024, China. ${ }^{b}$ State Key Laboratory of ElementoOrganic Chemistry, Nankai University, Tianjin 300071, China. ${ }^{c}$ Department of Chemistry, University of Pavia, Viale Taramelli 12, 27100, Pavia, Italy. ${ }^{d}$ Chemistry Research Laboratory, University of Oxford, 12 Mansfield Road, Oxford, OX1 3TA, U.K.

\begin{abstract}
An unprecedented conversion of terminal alkynes into $N$-sulfonimidamides (amidines) is reported, by a silvercatalyzed, one-pot, four-component reaction with $\mathrm{TMSN}_{3}$, sodium sulfinate, and sulfonyl azide. The reaction scope includes both aromatic and aliphatic alkynes. A possible cascade reaction mechanism, consisting of alkyne hydroazidation, sulfonyl radical addition, 1,3-dipolar cycloaddition by $\mathrm{TMSN}_{3}$, and a concerted $\mathrm{C}-\mathrm{C}$ and $\mathrm{N}-\mathrm{N}$ bond cleavage, is proposed. TMSN $\mathrm{T}_{3}$ is found to play an essential role in each step of the reaction.
\end{abstract}

\section{INTRODUCTION}

The development of novel functional group transformations of commonly available chemicals is of great importance in the development of general and readily applied synthetic methodologies. ${ }^{1}$ Alkynes are one example of a readily available chemical class; however the large dissociation energy required for the complete cleavage of the $\mathrm{C} \equiv \mathrm{C}$ triple bond $(\sim 200 \mathrm{kcal}$ $\mathrm{mol}^{-1}$ ) poses a challenge to the transformation of this functionality into other motifs. ${ }^{2}$ Most of the known examples of alkyne cleavage processes are involved in the construction of heterocycles and carbocycles. ${ }^{3,4}$ Far fewer strategies are available for the transformation of $\mathrm{C} \equiv \mathrm{C}$ triple bonds into other functional groups such as ketones, ${ }^{5,3 g}$ carboxylic esters and (thio)amides, ${ }^{6}$ olefins, ${ }^{7}$ alkynes, ${ }^{8}$ and nitriles ${ }^{9}$ (Figure 1a). Nevertheless, these procedures often require the use of activated alkynes or expensive and/or toxic transition metals. ${ }^{5-9}$ The development of functional group transformations starting from non-activated alkynes remains of high appeal.

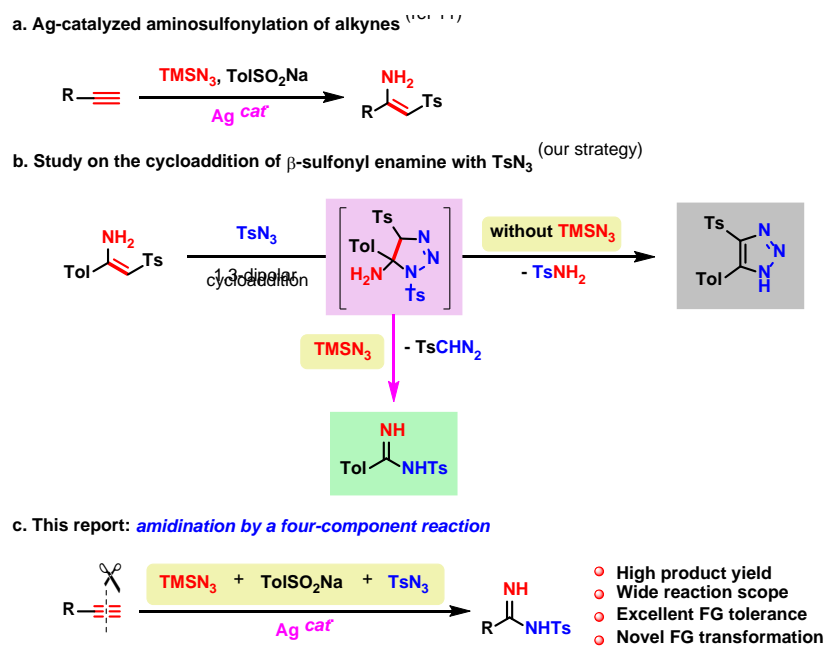

Figure 1. a. Previous transformations of alkynes into other functional groups. b. Previous work from our group on alkyne amino- sulfonylation. c. Transformation of $\beta$-sulfonyl enamine into an amidine. d. Reaction blueprint for the direct transformation of terminal alkynes into amidines.

Our group has recently developed a silver-catalyzed hydroazidation of terminal alkynes, which provides a method for the direct transformation of terminal alkynes to alpha-substituted vinyl azides. ${ }^{10}$ We subsequently reported a silver-catalyzed three-component reaction of terminal alkynes, trimethylsilyl azide $\left(\mathrm{TMSN}_{3}\right.$ ), and sodium sulfinate, which enables the synthesis of $\beta$-sulfonyl enamines (Figure 1b). ${ }^{11}$ The efficient generation of these enamines from terminal alkynes encouraged us to investigate their synthetic utility. One of the most studied reactions of enamines is their cycloaddition with sulfonyl azides, leading to triazoles. ${ }^{12}$ In the case of $\beta$-sulfonyl enamines, $\mathrm{TMSN}_{3}$ was found to play a crucial regulative role in the reaction of the in situ formed aminotriazole intermediate: in the absence of $\mathrm{TMSN}_{3}$ the anticipated triazole product was obtained, whereas in the presence of $\mathrm{TMSN}_{3}$ an amidine was unexpectedly isolated as the major product (Figure 1c). Notably, the amidination of free enamines with azides is unknown, ${ }^{13}$ despite the importance of amidines in azaheterocycle synthesis, ${ }^{14}$ molecular recognition, ${ }^{15}$ and pharmacophores in medicinal chemistry. ${ }^{16}$ Therefore, the development of an efficient synthetic method for amidines, especially for the iminylunprotected amidines, would be of great value. ${ }^{17}$ We envisaged that a novel cleavage transformation of the carboncarbon triple bond functionality into an amidine group could be achieved by a silver-catalyzed four-component reaction, directly starting from terminal alkynes with $\mathrm{TMSN}_{3}$, sodium sulfinate, and sulfonyl azide. Here we report the results of this investigation, which enables the synthesis of a wide range of $N$-sulfonimidamides (Figure 1c). ${ }^{18}$ To the best of our knowledge, this is the first report of the direct transformation of alkynes into amidines. ${ }^{19}$

\section{RESULTS AND DISCUSSION}

In an initial study, $p$-tolylacetylene 1a, $\mathrm{TMSN}_{3}$, sodium sulfinate 2a, tosyl azide $\mathbf{3 a}$ and water were reacted in the 
Table 1. Optimization of the Reaction Conditions ${ }^{a}$

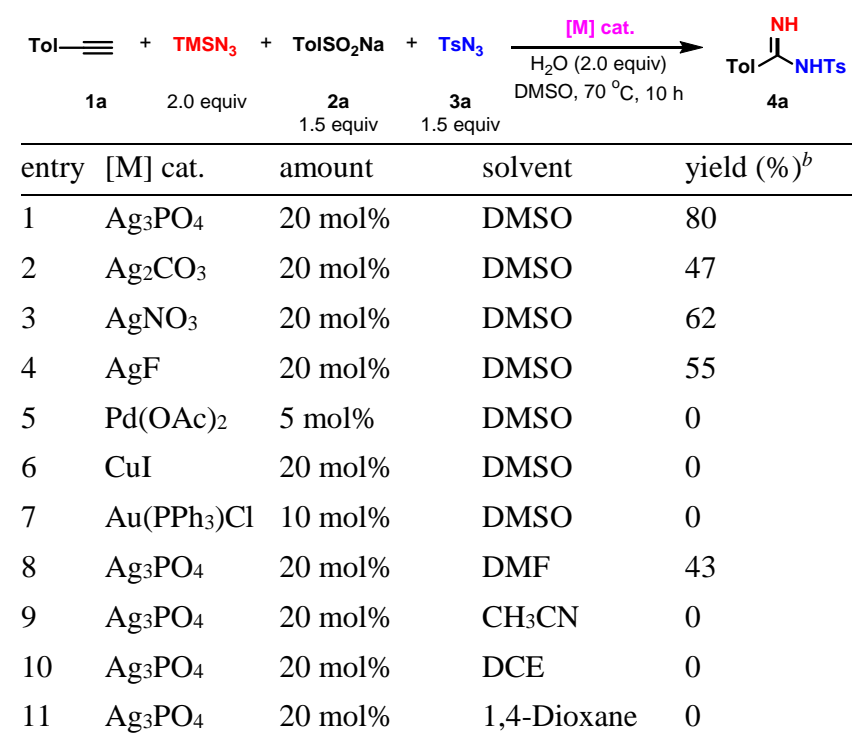

${ }^{a}$ Reaction conditions: 1a $(0.5 \mathrm{mmol}), \mathrm{TMSN}_{3}(1.0 \mathrm{mmol}), \mathrm{H}_{2} \mathrm{O}(1.0 \mathrm{mmol})$, $\mathrm{TolSO}_{2} \mathrm{Na} 2 \mathrm{a}(0.75 \mathrm{mmol}), \mathrm{TsN}_{3} 3 \mathrm{a}(0.75 \mathrm{mmol})$, catalyst $(0.1 \mathrm{mmol})$ in solvent $(3 \mathrm{~mL})$ at $70{ }^{\circ} \mathrm{C}$ under air for $10 \mathrm{~h} .{ }^{b}$ Isolated yields.

presence of $\mathrm{Ag}_{3} \mathrm{PO}_{4}$ catalyst in DMSO at $70{ }^{\circ} \mathrm{C}$, giving 4methyl- $N$-tosylbenzimidamide $\mathbf{4 a}$ in $80 \%$ yield (Table 1 ). This discovery prompted us to further optimize the reaction conditions for this $\mathrm{C} \equiv \mathrm{C}$ triple bond cleavage. In the absence of any one of the three reagents (TMSN ${ }_{3}, \mathrm{TolSO}_{2} \mathrm{Na}$, and $\mathrm{TsN}_{3}$ ), no product was obtained. When $\mathrm{Ag}_{3} \mathrm{PO}_{4}$ was replaced by other common silver salts such as $\mathrm{Ag}_{2} \mathrm{CO}_{3}, \mathrm{AgNO}_{3}$, and $\mathrm{AgF}$ (entries 2-4), no improvement in yield was recorded. Other transition-metal based catalysts, such as $\mathrm{Pd}(\mathrm{OAc})_{2}$, CuI, and $\mathrm{Au}\left(\mathrm{PPh}_{3}\right) \mathrm{Cl}$, did not show any activity (entries 5-7). The reaction outcome proved highly solvent dependent, with no detection of the desired product in $\mathrm{CH}_{3} \mathrm{CN}$, DCE or 1,4-dioxane, whereas in DMF product 4a was obtained in a modest $43 \%$ yield (entries 8-11). Notably, reducing or increasing the amount of $\mathrm{Ag}_{3} \mathrm{PO}_{4}$ resulted in lower product yields. The conditions listed in entry 1 were therefore optimal, and are termed 'standard conditions'.

With optimized conditions in hand, we sought to examine the reaction scope with respect to the alkyne substrate (Scheme 1). Aryl alkynes with either electron-donating or electron-withdrawing groups on the para-position of the phenyl ring proved to be competent for the $\mathrm{C} \equiv \mathrm{C}$ triple bond cleavage reaction, providing amidines $\mathbf{4 a}-\mathbf{4 m}$ in uniformly good yields. A variety of functional groups, such as alkoxy, halo, trifluoromethyl, cyano, ester, nitro, and formyl were well tolerated. The structure of the amidine products was further confirmed by X-ray crystallographic analysis of the product 4m. ${ }^{20}$ Meta-substituted aryl alkynes, as well as substrates with two substituents on the aryl ring, also afforded the desired products in 59\% to $85 \%$ yield (4n-4s). A phenol (4p) was also well tolerated under the cleavage reaction conditions. In addition, a naphthyl group was suitable for the preparation of amidine 4t (59\%). Heteroaryl alkynes, such as 3-quinolinyl, 2and 3-pyridyl, 2- and 3-thienyl, and dibenzo[b,d]thiophene-4yl, also participated in the reaction, affording the desired products $(\mathbf{4 u}-\mathbf{4 z})$ in $55 \%$ to $79 \%$ yield. As an example of application to the late-stage modification of more complex molecules, the methodology was successfully applied to 4-methyl umbelliferone and endofolliculina, affording the corresponding

Scheme 1. Reaction Scope of Aromatic Terminal Alkynes ${ }^{a}$

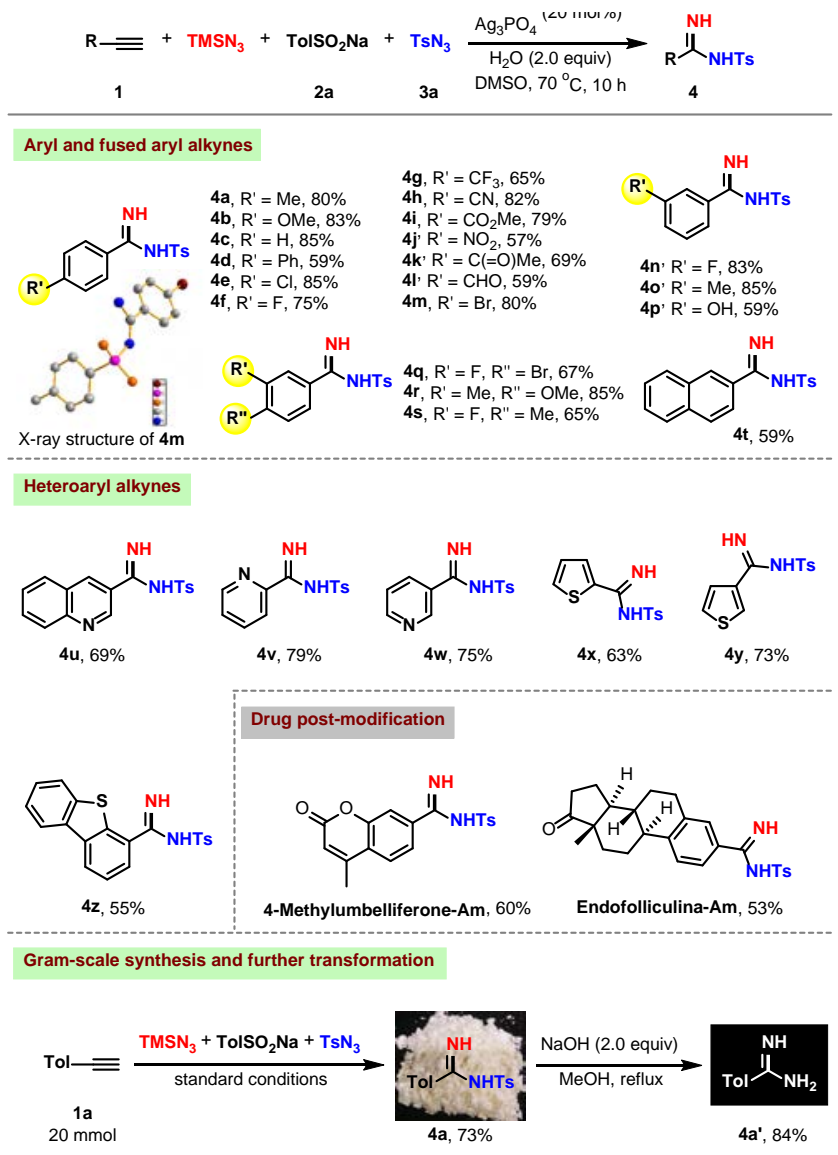

${ }^{a}$ Reaction conditions: 1 (0.5 mmol), TMSN 3 (1.0 mmol), TolSO ${ }_{2} \mathrm{Na}(0.75$ mmol), $\mathrm{TsN}_{3}(0.75 \mathrm{mmol})$, and $\mathrm{Ag}_{3} \mathrm{PO}_{4}(0.1 \mathrm{mmol})$ in DMSO $(3 \mathrm{~mL})$ at $70{ }^{\circ} \mathrm{C}$ under air for $10 \mathrm{~h}$; Yields of isolated products.

amidine-modified derivatives in moderate yield.

To test the large-scale applicability of this silver-catalyzed transformation, an experiment was performed where $20 \mathrm{mmol}$ of 1a was subjected to the standard reaction conditions, affording $N$-tosyl amidine $\mathbf{4 a}$ in a slightly reduced yield (73\%), which could be easily deprotected to amidine 4a' in $84 \%$ yield on treatment with $\mathrm{NaOH} .^{21}$

Our attention next turned to the reaction scope for aliphatic alkynes. As illustrated in Scheme 2, this class of substrates also underwent this transformation with similar efficiency, providing amidines in generally good yields. Terminal linear alkynes of varying chain length gave comparable reaction outcomes (5a-5d), as did the underivatized cycloalkylacetylenes (5e-5g) of varying ring size. Substrates with a variety of functional groups, such as ester, ether, thioether, phthalimide, and in particular an internal alkyne, also afforded the corresponding amidines (5h-5l) in 55\% to $82 \%$ yield, thus demonstrating chemoselectivity of this silver-catalyzed reaction for the terminal alkyne. The amidination of terminal alkynes was also effective with styryl acetylenes, leading to conjugated products $\mathbf{5 m}$ and $\mathbf{5 n}$ in comparable yields. When 3-butyn-1-ol was used as substrate, the unexpected sulfonylated amidine $\mathbf{5 0}$ was obtained in 55\% yield, possibly via a rarely described dehydroxysulfonation of the primary alcohol, ${ }^{22}$ followed by the amidination reaction. 
The scope for the sodium sulfinate and sulfonyl azide was

Scheme 2. Reaction Scope of Aliphatic Terminal Alkynes ${ }^{a}$

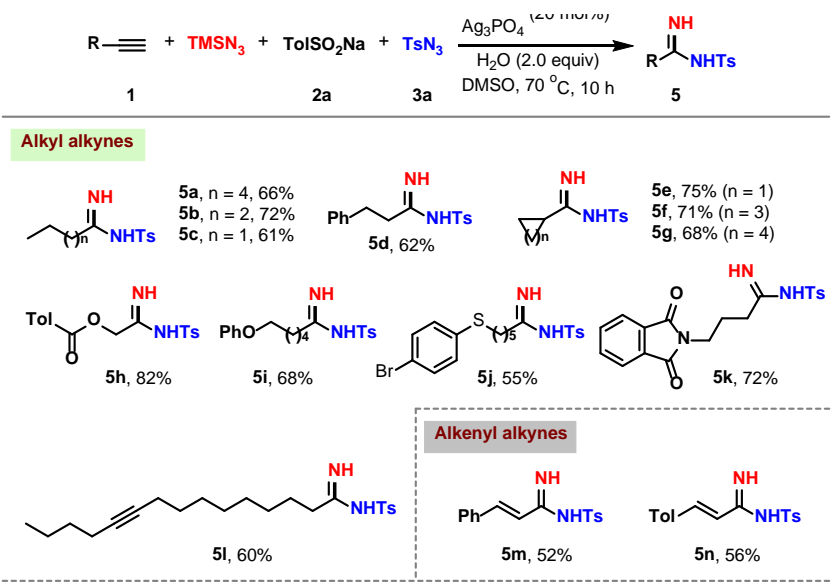

Dehydroxysulfonation/Amidination ${ }^{b}$

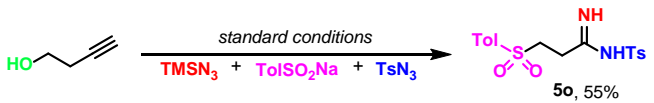

${ }^{a}$ Reaction conditions: 1 (0.5 mmol), TMSN 3 (1.0 mmol), TolsO ${ }_{2} \mathrm{Na}(0.75$ mmol), and $\mathrm{Ag}_{3} \mathrm{PO}_{4}(0.1 \mathrm{mmol})$ in DMSO $(2 \mathrm{~mL})$ at $70{ }^{\circ} \mathrm{C}$ for $4 \mathrm{~h}$, then $\mathrm{TsN}_{3}$ (0.75 mmol, dissolved in $1 \mathrm{~mL}$ DMSO), at $70{ }^{\circ} \mathrm{C}$ under air for a further $4-6 \mathrm{~h}$. Yield of isolated products. ${ }^{b}$ Two equivalents of $\mathrm{TolSO}_{2} \mathrm{Na}$ were used.

explored by testing the reaction of a small range of these components with $p$-tolylacetylene 1a (Table 2). When the sodium sulfinate and the sulfonyl azide featured the same substituent $\left(\mathrm{R}^{1}=\mathrm{R}^{2}\right.$, aryl or alkyl), the target amidines $(\mathbf{6 a}-\mathbf{6 f})$ were obtained in $67 \%$ to $85 \%$ yield. On performing the reaction with different groups on the sulfinate and sulfonate azide (i.e. $\mathrm{R}^{1} \neq \mathrm{R}^{2}$ ), amidines $\mathbf{6} \mathbf{g}$ ' and $\mathbf{6 h}$ ' were obtained as the sole products, with no detectable trace of the possible alternative product. This finding demonstrates that the sulfonamide unit in the product originates from the sulfonyl azide, rather than from the sulfinate, where the intermediate sulfone group is presumably lost in the course of alkyne cleavage.

Further experiments were carried out to gain a deeper understanding of the mechanistic pathway (Scheme 3): (a) Addit-

Table 2. Reaction Scope of Sodium Sulfinates and Sulfonyl Azides $^{a}$

\begin{tabular}{|c|c|c|c|c|}
\hline \multicolumn{2}{|c|}{$\underset{1 \mathrm{a}}{\mathrm{Tol}}=+\mathrm{TMSN}_{3}$} & $\frac{\mathrm{R}^{1} \mathrm{SO}_{2} \mathrm{Na}+\mathrm{R}^{2} \mathrm{SO}_{2} \mathrm{~N}_{3}}{\text { standard conditions }}$ & ${ }_{6}^{\mathrm{NH}} \mathrm{NHSO}_{2} \mathrm{R}^{1}$ & $+{ }_{\text {Tol }} \underbrace{\mathrm{NH}}_{6^{\prime}} \mathrm{NHSO}_{2} \mathrm{R}$ \\
\hline entry & $\mathrm{R}^{1}$ & $\mathrm{R}^{2}$ & $6=6^{\prime}$ & Yield (\%) ${ }^{b}$ \\
\hline 1 & $4-\mathrm{MeOC}_{6} \mathrm{H}_{4}$ & $4-\mathrm{MeOC}_{6} \mathrm{H}_{4}$ & $6 a$ & 74 \\
\hline 2 & $\mathrm{Ph}$ & $\mathrm{Ph}$ & $6 b$ & 67 \\
\hline 3 & $4-\mathrm{ClC}_{6} \mathrm{H}_{4}$ & $4-\mathrm{ClC}_{6} \mathrm{H}_{4}$ & $6 c$ & 75 \\
\hline 4 & $4-\mathrm{FC}_{6} \mathrm{H}_{4}$ & $4-\mathrm{FC}_{6} \mathrm{H}_{4}$ & 6d & 78 \\
\hline 5 & Oct & Oct & $6 e$ & 82 \\
\hline 6 & $\mathrm{Me}$ & $\mathrm{Me}$ & $6 f$ & 85 \\
\hline 7 & $\mathrm{Me}$ & $4-\mathrm{MeC}_{6} \mathrm{H}_{4}$ & $6 \mathrm{~g} 0$ & 6g' 80 \\
\hline 8 & 4- $\mathrm{MeC}_{6} \mathrm{H}_{4}$ & $4-\mathrm{ClC}_{6} \mathrm{H}_{4}$ & 6h 0 & 6h' 75 \\
\hline
\end{tabular}

${ }^{a}$ Reaction conditions: 1 (0.5 mmol), TMSN $3(1.0 \mathrm{mmol}), \mathrm{R}^{1} \mathrm{SO}_{2} \mathrm{Na} 2(0.75$ $\mathrm{mmol}), \mathrm{R}^{2} \mathrm{SO}_{2} \mathrm{~N}_{3} 3$ (0.75 mmol), and $\mathrm{Ag}_{3} \mathrm{PO}_{4}(0.1 \mathrm{mmol})$ in DMSO (3 mL) at $70{ }^{\circ} \mathrm{C}$ under air for 8-10 h; ${ }^{b}$ Yields of isolated products.

\section{Scheme 3. Mechanistic Investigations}

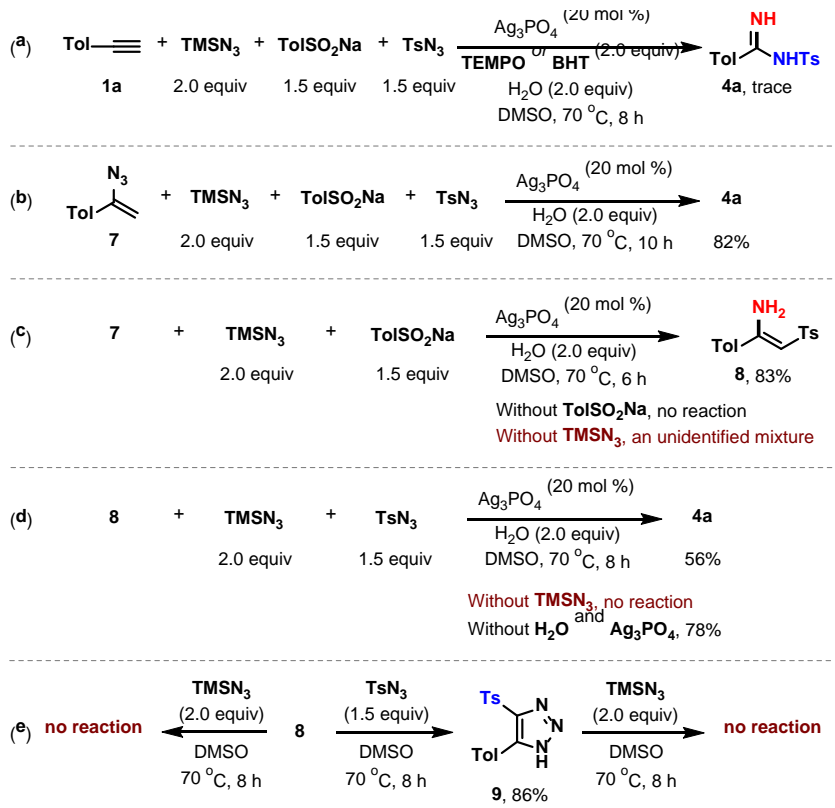

ion of the radical traps 2,2,6,6-(tetramethylpiperidin-1-yl)oxyl (TEMPO) or butylated hydroxytoluene (BHT) to the reaction under the optimized conditions led to the formation of only a trace amount of product 4a, thus implying the possible involvement of a radical process. (b) When terminal alkyne 1a was replaced by vinyl azide 7, 4a was obtained in a yield (82\%) comparable to that in theanalogous optimized one-pot conditions (c.f. Table 1, entry 1), thus suggesting the vinyl azide as a potential initial reaction intermediate. (c) When vinyl azide 7 was subjected to the optimized reaction conditions but in the absence of $\mathrm{TsN}_{3}$, the aminosulfonylated product 8 was obtained in 83\% yield, and amidine $\mathbf{4 a}$ was not detected. Moreover, no product $\mathbf{8}$ could be observed when the reaction was carried out in the absence of either $\mathrm{TolSO}_{2} \mathrm{Na}$ or $\mathrm{TMSN}_{3}$. (d) When 8 was subjected to the optimized conditions (but in the absence of the sulfinate salt), $4 \mathbf{a}$ was isolated in $56 \%$ yield, implying 8 also to be a reaction intermediate. No reaction occurred without $\mathrm{TMSN}_{3}$, thus confirming this reactant as essential for conversion to the amidine. Moreover, the silver catalyst and water seemed to be detrimental to this particular reaction, with an improved $78 \%$ yield of $\mathbf{4 a}$ attained in their absence. (e) The cycloaddition of enamine 8 with $\mathrm{TsN}_{3}$, but in the absence of $\mathrm{TMSN}_{3}$, led to triazole product 9 in $86 \%$ yield. No reaction was observed on treatment of $\mathbf{9}$ with $\mathrm{TMSN}_{3}$, suggesting that $\mathbf{9}$ is not an intermediate in the formation of the amidine product.

Based on the above results and related precedent, ${ }^{12 a, 23}$ a plausible mechanism for the amidination of tolylacetylene 1a is outlined in Scheme 4. As demonstrated in Scheme 3c, tosyl enamine $\mathbf{8}$ is first formed from the reaction of $\mathbf{1 a}$ with $\mathrm{TMSN}_{3}$ and $\mathrm{TolSO}_{2} \mathrm{Na}$ under silver catalysis, through sequential hydroazidation of the terminal alkyne, and aminosulfonylation by sulfonyl radical addition to the in situ generated vinyl azide. ${ }^{11}$ 1,3-dipolar cycloaddition with $\mathrm{TsN}_{3}$ gives 1,2,3triazoline intermediate $\mathbf{A},{ }^{13 a}$ which undergoes a retro-[3+2] cycloaddition to yield the imidamide $\mathbf{B}$, with elimination of 
$\mathrm{TsCHN}_{2}{ }^{13 \mathrm{~b}}$ In light of the result in Scheme 3e, $\mathrm{TMSN}_{3}$ appears to play a critical role in the chemoselectivity of this cleavage process, favoring the retro-cycloaddition over elimination of ammonia, although the exact mechanism of this step remains unclear.

\section{Scheme 4. Proposed Mechanism}

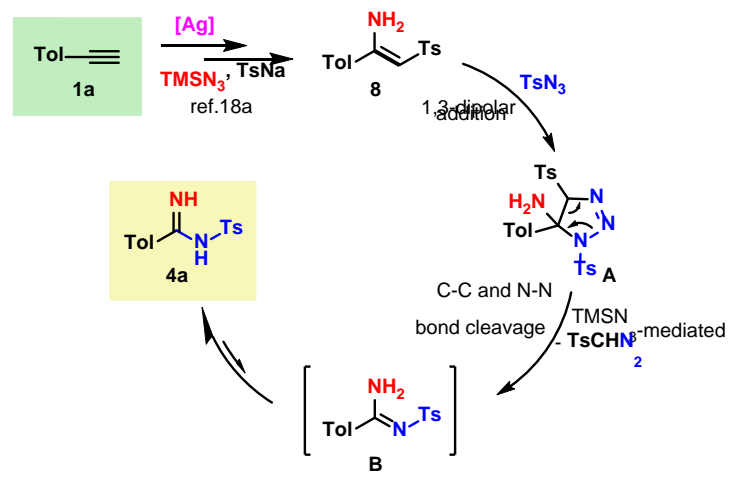

Finally, tautomerization of imidamide $\mathbf{B}$ gives rise to product 4a.

\section{CONCLUSION}

In conclusion, we have developed an unprecedented silvercatalyzed $\mathrm{C} \equiv \mathrm{C}$ cleavage of terminal alkynes to amidines by a one-pot four-component reaction. The reaction accommodates a wide variety of aryl, heteroaryl, alkyl, and alkenylsubstituted terminal alkynes and tolerates a range of other functional groups. From a mechanistic perspective, a cascade sequence is proposed consisting hydroazidation, sulfonyl radical addition, 1,3-dipolar cycloaddition, and a retro-1,3-dipolar cycloaddition, resulting in the amidine product. Given the importance of amidines in medicinal chemistry research, this process offers a facile entry to this useful functional group.

\section{ASSOCIATED CONTENT}

\section{Supporting Information}

Experimental procedures, analytical data, and copies of NMR spectra are available free of charge via the Internet at (http://pubs.acs.org/page/jacsat/submission/authors.html).

\section{AUTHOR INFORMATION}

\section{Corresponding Author \\ E-Mail: bixh507@nenu.edu.cn}

\section{Notes}

The authors declare no competing financial interest. $\S$ These authors contributed equally to this work.

\section{ACKNOWLEDGMENT}

Financial support was provided by NSFC (21871043, 21522202, 21502017) and the Department of Science and Technology of Jilin Province (20180101185JC, 20190701012GH). E.A.A. thanks the EPSRC for support (EP/M019195/1).

\section{REFERENCES}

(1) (a) Katritzky, A. R.; Taylor, R. J. K. Comprehensive Organic Functional Group Transformations, 1st ed.; Elsevier: Amsterdam, Netherlands, 2005. (b) Richard, C. L. Comprehensive Organic Trans- formations: A Guide to Functional Group Preparations, 2nd ed.; Wiley-VCH: New York, NY, 1999.

(2) (a) Haines, A. H. Methods for the Oxidation of Organic Compounds. Alkanes, Alkenes, Alkynes, and Arenes; Academic Press: New York, 1985. (b) Dong, G., Ed. $C-C$ bond activation; Springer Verlag: Berlin/Heidelberg, 2014. (c) Jun, C.-H. Transition Metal-Catalyzed Carbon-Carbon Bond Activation. Chem. Soc. Rev. 2004, 33, 610. (d) Wang, T.; Jiao, N. Direct Approaches to Nitriles via Highly Efficient Nitrogenation Strategy through $\mathrm{C}-\mathrm{H}$ or $\mathrm{C}-\mathrm{C}$ Bond Cleavage. Acc. Chem. Res. 2014, 47, 1137.

(3) For the synthesis of heterocycles, see: (a) Shimada, T.; Yamamoto, Y. Carbon-Carbon Bond Cleavage of Diynes through the Hydroamination with Transition Metal Catalysts. J. Am. Chem. Soc. 2003, 125, 6646. (b) Yan, H.; Wang, H.; Li, X.; Xin, X.; Wang, C.; Wan, B. Rhodium-Catalyzed C-H Annulation of Nitrones with Alkynes: A Regiospecific Route to Unsymmetrical 2,3-DiarylSubstituted Indoles. Angew. Chem. Int. Ed. 2015, 54, 10613. (c) Xie, H.-Z.; Gao, Q.; Liang, Y.; Wang, H.-S.; Pan, Y.-M. PalladiumCatalyzed Synthesis of Benzoxazoles by the Cleavage Reaction of Carbon-Carbon Triple Bonds with o-Aminophenol. Green Chem. 2014, 16, 2132. (d) Liu, Q.; Chen, P.; Liu, G. Palladium-Catalyzed $\mathrm{C}-\mathrm{C}$ Triple Bond Cleavage: Efficient Synthesis of $4 \mathrm{H}-$ Benzo[d][1,3]oxazin-4-ones. ACS Catal. 2013, 3, 178. (e) Huang, Y.; Yan, D.; Wang, X.; Zhou, P.; Wu, W.; Jiang, H. Controllable Assembly of the Benzothiazole Framework Using a $\mathrm{C} \equiv \mathrm{C}$ triple Bond as a One-carbon Synthon. Chem. Commun. 2018, 54, 1742. (f) Sun, J.; Wang, F.; Hu, H.; Wang, X.; Wu, H.; Liu, Y. Copper(II)-Catalyzed Carbon-Carbon Triple Bond Cleavage of Internal Alkynes for the Synthesis of Annulated Indolizines. J. Org. Chem. 2014, 79, 3992. (g) Wang, J.-Y.; Zhou, P.; Li, G.; Hao, W.-J.; Tu, S.-J.; Jiang, B. Synthesis of Functionalized Benzo[g]indoles and 1-Naphthols via Carbon-Carbon Triple Bond Breaking/Rearranging. Org. Lett. 2017, 19, 6682. (h) Liu, Y.; Song, F.; Guo, S. Cleavage of a Carbon-Carbon Triple Bond via Gold-Catalyzed Cascade Cyclization/Oxidative Cleavage Reactions of (Z)-Enynols with Molecular Oxygen. J. Am. Chem. Soc. 2006, 128, 11332. (i) Prakash, R.; Bora, B. R.; Boruah, R. C.; Gogoi, S. Ru(II)-Catalyzed C-H Activation and Annulation Reaction via Carbon-Carbon Triple Bond Cleavage. Org. Lett. 2018, 20, 2297.

(4) For the synthesis of carbocycles, see: (a) Miyanohana, Y.; Chatani, N. Skeletal Reorganization of Enynes Catalyzed by $\mathrm{InCl}_{3}$. Org. Lett. 2006, 8, 2155. (b) Li, H.; Hao, W.-J.; Wang, M.; Qin, X.; Tu, S.-J.; Zhou, P.; Li, G.; Wang, J.; Jiang, B. Catalytic Double [2 + 2] Cycloaddition Relay Enabled $\mathrm{C}-\mathrm{C}$ Triple Bond Cleavage of Yne-Allenones, Org. Lett. 2018, 20, 4362.

(5) (a) Lee, D.-Y.; Hong, B.-S.; Cho, E.-G.; Lee, H.; Jun, C.-H. A Hydroacylation-Triggered Carbon-Carbon Triple Bond Cleavage in Alkynes via Retro-Mannich Type Fragmentation. J. Am. Chem. Soc. 2003, 125, 6372. (b) Jun, C.-H.; Lee, H.; Moon, C. W.; Hong, H.-S. Cleavage of Carbon-Carbon Triple Bond of Alkyne via Hydroiminoacylation by Rh(I) Catalyst. J. Am. Chem. Soc. 2001, 123, 8600. (c) Zhou, P.; Wang, J.-Y.; Zhang, T.-S.; Li, G.; Hao, W.-J.; Tu, S.-J.; Jiang, B. Thiazolium Saltcatalyzed $\mathrm{C}-\mathrm{C}$ Triple Bond Cleavage for Accessing Substituted 1Naphthols via Benzannulation. Chem. Commun. 2018, 54, 164. (d) Sagadevan, A.; Charpe, V. P.; Ragupathi, A.; Hwang, K. C. Visible Light Copper Photoredox-Catalyzed Aerobic Oxidative Coupling of Phenols and Terminal Alkynes: Regioselective Synthesis of Functionalized Ketones via $\mathrm{C} \equiv \mathrm{C}$ Triple Bond Cleavage. J. Am. Chem. Soc. 2017, 139, 2896. (e) Okamoto, N.; Sueda, T.; Minami, H.; Miwa, Y.; Yanada, R. Regioselective Iodoazidation of Alkynes: Synthesis of $\alpha, \alpha$-Diazidoketones. Org. Lett. 2015, 17, 1336.

(6) (a) Wang, A.; Jiang, H. Palladium-Catalyzed Cleavage Reaction of Carbon-Carbon Triple Bond with Molecular Oxygen Promoted by Lewis Acid. J. Am. Chem. Soc. 2008, 130, 5030. (b) Khamarui, S.; Maiti, R.; Maiti, D. K. General Base-tuned Unorthodox Synthesis of Amides and Ketoesters with Water. Chem. Commun. 2015, 51, 384. (c) Dighe, S. U.; Batra, S. Visible Light-Induced Iodine-Catalyzed Transformation of Terminal Alkynes to Primary Amides via $\mathrm{C} \equiv \mathrm{C}$ Bond Cleavage under Aqueous Conditions. Adv. Synth. Catal. 2016, 358, 500. (d) Xu, K.; Li, Z.; Cheng, F.; Zuo, Z.; Wang, T.; Wang, M.; Liu, L. Transition-Metal-Free Cleavage of $\mathrm{C}-\mathrm{C}$ Triple Bonds in Aromatic Alkynes with $\mathrm{S}_{8}$ and Amides Leading to Aryl Thioamides. Org. Lett. 2018, 20, 2228. 
(7) Datta, S.; Chang, C.-L.; Yeh, K.-L.; Liu, R.-S. A New RutheniumCatalyzed Cleavage of a Carbon-Carbon Triple Bond: Efficient Transformation of Ethynyl Alcohol into Alkene and Carbon Monoxide. J. Am. Chem. Soc. 2003, 125, 9294.

(8) For reviews, see: (a) Bunz, U. H. F. Poly(p-phenyleneethynylene)s by Alkyne Metathesis. Acc. Chem. Res. 2001, 34, 998. (b) Fürstner, A.; Mathes, C.; Lehmann, C. W. Alkyne Metathesis: Development of a Novel Molybdenum-Based Catalyst System and Its Application to the Total Synthesis of Epothilone A and C. Chem. Eur. J. 2001, 7, 5299. (c) Fürstner, A.; Davies, P. W. Alkyne Metathesis. Chem. Commun. 2005, 0, 2307. (d) Villar, H.; Frings, M.; Bolm, C. Ring Closing Enyne Metathesis: A Powerful Tool for the Synthesis of Heterocycles. Chem. Soc. Rev. 2007, 36, 55. (e) Zhang, W.; Moore, J. S. Alkyne Metathesis: Catalysts and Synthetic Applications. Adv. Synth. Catal. 2007, 349, 93.

(9) (a) Shen, T.; Wang, T.; Qin, C.; Jiao, N. Silver-Catalyzed Nitrogenation of Alkynes: A Direct Approach to Nitriles through $\mathrm{C} \equiv \mathrm{C}$ Bond Cleavage. Angew. Chem. Int. Ed. 2013, 52, 6677. (b) Okamoto, N.; Ishikura, M.; Yanada, R. Cleavage of Carbon-Carbon Triple Bond: Direct Transformation of Alkynes to Nitriles. Org. Lett. 2013, 15, 2571. (c) Dutta, U.; Lupton, D. W.; Maiti, D. Aryl Nitriles from Alkynes Using tertButyl Nitrite: Metal-Free Approach to $\mathrm{C} \equiv \mathrm{C}$ Bond Cleavage. Org. Lett. 2016, 18, 860. (d) Lin, Y.; Song, Q. Cleavage of the Carbon-Carbon Triple Bonds of Arylacetylenes for the Synthesis of Arylnitriles without a Metal Catalyst. Eur. J. Org. Chem. 2016, 3056. (e) Geyer, A. M.; Gdula, R. L.; Wiedner, E. S.; Johnson, M. J. A. Catalytic Nitrile-Alkyne CrossMetathesis. J. Am. Chem. Soc. 2007, 129. 3800.

(10) (a) Liu, Z.; Liu, J.; Zhang, L.; Liao, P.; Song J.; Bi, X. Silver(I) Catalyzed Hydroazidation of Ethynyl Carbinols: Synthesis of 2-Azidoallyl Alcohols. Angew. Chem. Int. Ed. 2014, 53, 5305. (b) Liu, Z.; Liao, P.; Bi, X. General Silver-Catalyzed Hydroazidation of Terminal Alkynes by Combining TMS-N3 and H2O: Synthesis of Vinyl Azides. Org. Lett. 2014, 16, 3668.

(11) Ning, Y.; Ji, Q.; Liao, P.; Anderson, E. A.; Bi, X. SilverCatalyzed Stereoselective Aminosulfonylation of Alkynes. Angew. Chem. Int. Ed. 2017, 56, 13805.

(12) For a review, see: (a) Bakulev, V. A.; Beryozkina, T.; Thomas, J.; Dehaen, W. The Rich Chemistry Resulting from the 1,3-Dipolar Cycloaddition Reactions of Enamines and Azides. Eur. J. Org. Chem. 2018, 262. See also: (b) Iminov, R. T.; Mashkov, A. V.; Chalyk, B. A.; Mykhailiuk, P. K.; Tverdokhlebov, A. V.; Tolmachev, A. A.; Volovenko, Y. M.; Shishkin, O. V.; Shishkina, S. V. A Convenient Route to 1-Alkyl-5trifluoromethyl-1,2,3-triazole-4-carboxylicAcids Employing a Diazo Transfer Reaction. Eur. J. Org. Chem. 2013, 2891. (c) Cheng, G.; Zeng, X.; Shen, J.; Wang, X.; Cui, X. A Metal-Free Multicomponent Cascade Reaction for the Regiospecific Synthesis of 1,5-Disubstituted 1,2,3Triazoles. Angew. Chem. Int. Ed. 2013, 52, 13265. (d) Wan, J.-P.; Cao, S.; Liu, Y. A Metal- and Azide-Free Multicomponent Assembly toward Regioselective Construction of 1,5-Disubstituted 1,2,3-Triazoles. J. Org. Chem. 2015, 80, 9028. For a seminal publication, see: (e) Fusco, R.; Bianchetti, G.; Pocar, D.; Ugo, R. Versuche im Enamingebiet, VII. Reaktionen von Arylsulfonylaziden mit Enaminen aus Ketomethylenverbindungen. Chem. Ber 1963, 802.

(13) For examples of the amidination of $\mathrm{N}$-protected enamines with sulfonyl azides, see: (a) Gao, T.; Zhao, M.; Meng, X.; Li, C.; Chen, B. Facile Synthesis of Sulfonyl Amidines and $\beta$-Amino Sulfonyl Enamines under Transition-Metal-Free Conditions. Synlett 2011, 1281. (b) Xu, Y.; Wang, Y.; Zhu, S. Reactions of Per(poly)-Fluoroalkanesulfonyl Azides with $\beta$-ketoester Enamines, A New Route to $\mathrm{N}$ Per(poly)Fluoroalkanesulfonyl Amidines. J. Fluorine Chem. 2000, 104, 195. (c) Contini, A.; Erba, E.; Pellegrino, S. Multicomponent Synthesis of Pentyl-Sulfonyl Amidines via Diazoalkane. Synlett 2012, 1523. (d) Xu, X.; Li, X.; Ma, L.; Ye, N.; Weng, B. An Unexpected Diethyl Azodicarboxylate-Promoted Dehydrogenation of Tertiaryamine and Tandem Reaction with Sulfonyl Azide. J. Am. Chem. Soc. 2008, 130, 14048. (e) Xu, X.; Ge, Z.; Cheng, D.; Ma, L.; Lu, C.; Zhang, Q.; Yao, N.; Li, X. CuCl/CCl4Promoted Convenient Synthesis of Sulfonyl Amidines from Tertiary Amines and Sulfonyl Azides. Org. Lett. 2010, 12, 897. (f) Kumar, Y. K.; Kumar, G. R.; Reddy, T. J.; Sridhar, B.; Reddy, M. S. Synthesis of 3Sulfonylamino Quinolines from 1-(2-Aminophenyl)Propargyl Alcohols through a Ag(I)-Catalyzed Hydroamination, $(2+3)$ Cycloaddition, and an Unusual Strain-Driven Ring Expansion. Org. Lett. 2015, 17, 2226.

(14) (a) Duerfeldt, A. S.; Boger, D. L. Total Syntheses of (-)Pyrimidoblamic Acid and P-3A. J. Am. Chem. Soc. 2014, 136, 2119. (b) Fukuyama, T.; Nakashima, N.; Okada, T.; Ryu, I. Free-Radical-Mediated
$[2+2+1]$ Cycloaddition of Acetylenes, Amidines, and CO Leading to Five-Membered $\alpha, \beta$-Unsaturated Lactams. J. Am. Chem. Soc. 2013, 135, 1006. (c) Wang, Y.-F.; Chen, H.; Zhu, X.; Chiba, S. Copper-Catalyzed Aerobic Aliphatic C-H Oxygenation Directed by an Amidine Moiety. J. Am. Chem. Soc. 2012, 134, 11980. (d) Zhu, Y.; Nikolic, D.; Van Breemen, R. B.; Silverman, R. B. Mechanism of Inactivation of Inducible Nitric Oxide Synthase by Amidines. Irreversible Enzyme Inactivation without Inactivator Modification. J. Am. Chem. Soc. 2005, 127, 858.

(15) (a) Okano, A.; James, R. C.; Pierce, J. G.; Xie, J.; Boger, D. L. Silver(I)-Promoted Conversion of Thioamides to Amidines: Divergent Synthesis of a Key Series of Vancomycin Aglycon Residue 4 Amidines That Clarify Binding Behavior to Model Ligands. J. Am. Chem. Soc. 2012 134, 8790. (b) Yamada, H.; Furusho, Y.; Yashima, E. Diastereoselective Imine-Bond Formation through Complementary Double-Helix Formation. J. Am. Chem. Soc. 2012, 134, 7250. (c) Munde, M.; Lee, M.; Neidle, S.; Arafa, R.; Boykin, D. W.; Liu, Y.; Bailly, C.; Wilson, W. D. Induced Fit Conformational Changes of a "Reversed Amidine" Heterocycle: Optimized Interactions in a DNA Minor Groove Complex. J. Am. Chem. Soc. 2007, 129, 5688.

(16) (a) Patrick, D. A.; Ismail, M. A.; Arafa, R. K.; Wenzler, T.; Zhu, X.; Pandharkar, T.; Jones, S. K.; Werbovetz, K. A.; Brun, R.; Boykin, D. W.; Tidwell, R. R. Synthesis and Antiprotozoal Activity of Dicationic $\mathrm{m}$-Terphenyl and 1,3-Dipyridylbenzene Derivatives. J. Med. Chem. 2013, 56, 5473. (b) Meiering, S.; Inhoff, O.; Mies, J.; Vincek, A.; Garcia, G.; Kramer, B.; Dormeyer, M.; Krauth-Siegel, R. L. Inhibitors of Trypanosoma cruzi Trypanothione Reductase Revealed by Virtual Screening and Parallel Synthesis. J. Med. Chem. 2005, 48, 4793.

(17) Very few methods are available for the synthesis of $\mathrm{N}$ unprotected amidines, for example, see: (a) Sävmarker, J.; Rydfjord, J.; Gising, J.; Odell, L. R.; Larhed, M. Direct Palladium(II)-Catalyzed Synthesis of Arylamidines from Aryltrifluoroborates. Org. Lett. 2012, 14, 2394. (b) Baeten, M.; Maes, B. U. W. Guanidine Synthesis: Use of Amidines as Guanylating Agents. Adv. Synth. Catal. 2016, 358, 826.

(18) The synthetic methods for $N$-sulfonylimidamides are rarely developed, see: (a) Dubina, V. L.; Shebitchenko, L. N.; Pedan, V. P.; Yukhno, A. G.; Skripets, V. I. N2-(Arylsulfonyl)Arylamidines. Synthesis and Properties of $\mathrm{N}_{2}$-(Arylsulfonyl)Arylamidines and Their $\mathrm{N}_{1}$ Acyl Derivatives. Russ. J. Org. Chem. 1982, 18, 793. (b) Baeten, M.; Maes, B. U. W. Guanidine Synthesis: Use of Amidines as Guanylating Agents. Adv. Synth. Catal. 2016, 358, 826.

(19) (a) Fang, G.; Bi, X. Silver-Catalysed Reactions of Alkynes: Recent Advances. Chem. Soc. Rev. 2015, 44, 8124. (b) Kolle, S.; Batra. S. Transformations of Alkynes to Carboxylic Acids and Their Derivatives via $\mathrm{C} \equiv \mathrm{C}$ bond Cleavage. Org. Biomol. Chem. 2016, 14, 11048.

(20) CCDC 1869371 (4m) contains the supplementary crystallographic data for this paper. These data can be obtained free of charge from The Cambridge Crystallographic Data Centre via www. ccdc.cam.ac.uk/data_request/cif.

(21) Zhang, B.-H.; Lei, L.-S.; Liu, S.-Z.; Mou, X.-Q.; Liu, W.-T.; Wang, S.-H.; Wang, J.; Bao, W.; Zhang, K. Zinc-Promoted Cyclization of Tosylhydrazones and 2-(Dimethylamino)Malononitrile: an Efficient Strategy for the Synthesis of Substituted 1-Tosyl-1HPyrazoles. Chem. Commun. 2017, 53, 8545.

(22) (a) Liu, J.; Liu, Z.; Liao, P.; Bi, X. Modular Synthesis of Sulfonyl Benzoheteroles by Silver-Catalyzed Heteroaromatization of Propargylic Alcohols with $p$-Toluenesulfonylmethyl Isocyanide (TosMIC): Dual Roles of TosMIC. Org. Lett. 2014, 16, 6204. (b) Kloeppner, L. J.; Duran, R. S. Langmuir Film Polymerization of 1,22-Bis(2-aminophenyl)docosane: A Two-Dimensional Cross-linked Polyalkylaniline. J. Am. Chem. Soc. 1999, 121, 8108; (c) Murakami, T.; Furusawa, K. One-Pot Synthesis of Aryl Sulfones from Alcohols. Synthesis 2002, 4, 479. (d) Klester, A. M.; Ganter, C. The Adamantane Rearrangement of 1,2Trimethylenenorbornanes. III). $\mathrm{AlBr}_{3}$-catalyzed Rearrangement to 2,6Trimethylenenorbornane. Helv. Chim. Acta. 1983, 66, 1200.

(23) For a recent review on vinyl azide chemistry, see: Fu, J.; Zanoni, G.; Anderson, E. A.; Bi, X. $\alpha$-Substituted vinyl azides: an emerging functionalized alkene. Chem. Soc. Rev. 2017, 46, 7208. 


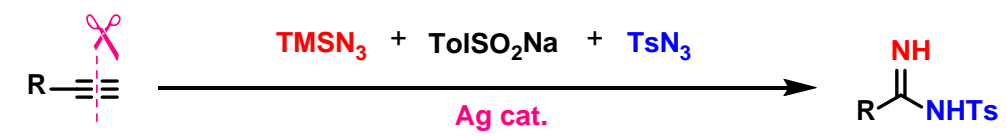

$\mathbf{R}=($ Het)Aryl $\quad \sqrt{ } \mathrm{C} \equiv \mathrm{C}$ triple bond cleavage 51 examples

Alkyl, Alkenyl $\checkmark$ good functional group tolerance up to $85 \%$ yield $\checkmark$ high efficiency and high product yield 